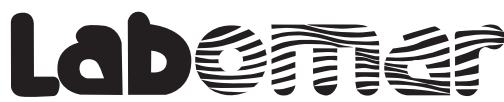

Arquivos de Ciências do Mar

\section{AÇÃO DOS CONDIMENTOS ALIMENTARES IN MATURA SOBRE A MICROBIOTA PATÓGENA DURANTE O PROCESSAMENTO, PREPARO E/OU CONSUMO DO PESCADO: UMA REVISÃO SISTEMÁTICA DE LITERATURA}

\author{
In natura action of spices in food on pathogenic microbiota \\ during the processing, preparation and/or consumption \\ of fish: a systematic literature review \\ Luiz Antonio Costa Tarcitano1; Eliana de Fatima Marques de Mesquita² \\ ${ }^{1}$ Médico Veterinário, Mestrando do Departamento de Tecnologia de Alimentos, Faculdade de Veterinária, \\ Universidade Federal Fluminense - UFF, Niterói, RJ, Brasil. E-mail: latarcitano@globo.com \\ 2 Médica Veterinária, Professora Doutora do Departamento de Tecnologia de Alimentos, Faculdade de Veterinária, \\ Universidade Federal Fluminense - UFF, Niterói, RJ, Brasil. E-mail: elianafmmpescado@gmail.com
}

\begin{abstract}
RESUMO
A Segurança Alimentar visa garantir à população acesso físico e econômico a alimentos inócuos e nutritivos. Esta pesquisa objetivou investigar a ocorrência de atividade antimicrobiana nos condimentos alimentares in natura utilizados no processamento, preparo e/ou consumo do pescado, por meio de uma revisão sistemática de literatura e abrange artigos publicados até julho de 2016. A busca foi realizada nas bases de dados eletrônicas LILACS; MEDLINE, SciELO; Google Acadêmico; CAPES, Cochrane Library; Scopus; ScienceDirect; PubMed. A inclusão dos artigos na revisão sistemática foi guiada pelo Preferred Reporting Items for Systematic Reviews and Meta-Analyses (PRISMA) e o Assessment of Multiple Systematic Reviews (AMSTAR). A intepretação dos textos selecionados foi feita por meio de análise estatística descritiva e expressa em Figuras, quadros, diagrama de dispersão de dados e gráfico Box Plot, utilizando-se o programa IBM SPSSStatistics Base 22.0. Dos textos inicialmente identificados, 21 artigos foram considerados elegíveis para a revisão. Infere-se que a utilização das especiarias são uma boa opção no combate ao crescimento de bactérias, leveduras, fungos filamentosos e síntese de toxinas microbianas, bem como na inibição ou retardamento da oxidação do pescado. Similarmente, orégano, alecrim e sálvia foram os condimentos de maior efetividade antimicrobiana.
\end{abstract}

Palavras-chave: condimentos, especiarias, atividade antimicrobiana, pescado.

Recebido: 4 set 2016

Aceito: 16 dez 2016

Publicado online: 31 mai 2017 


\begin{abstract}
Food Safety seeks to guarantee the physical and economical access to non-harmful and nutritious foods to the population. The present study aimed to investigate the in natura antimicrobial activity of food seasonings used in the processing, preparation and/or consumption of fish through a systematic literature review of identified articles published by July 2016. The search was carried out in the LILACS; MEDLINE, SciELO; Google Scholar; CAPES, Cochrane Library; Scopus; ScienceDirect; and PubMed electronic databases. The inclusion of articles in the systematic review was based on the Preferred Reporting Items for Systematic Reviews and Meta-Analyzes (PRISMA) and the Assessment of Multiple Systematic Reviews (AMSTAR). The interpretation of the selected texts was performed through descriptive statistical analysis and expressed in illustrations, tables, data dispersion diagrams and a Box Plot graph, using the IBM SPSS Statistics Base 22.0 program. Of the initially identified manuscripts, 21 articles were eligible for review. The selected literature suggests that spices are an effective choice for combating the growth of bacteria, yeasts, filamentous fungi and microbial toxin synthesis, as well as the inhibition or retardation of the oxidation of fish. Additionally, the condiments oregano, rosemary and sage exhibited the most effective antimicrobial activity.
\end{abstract}

Keywords: condiments, spices, antimicrobial activity, fish.

\title{
INTRODUÇÃO
}

De acordo com o Regulamento da Inspeção Industrial e Sanitária de Produtos de Origem Animal - RIISPOA (BRASIL, 1952), o vocábulo “pescado" é uma denominação genérica e compreende "peixes, crustáceos, moluscos, anfíbios, quelônios e mamíferos de água doce ou salgada, usados na alimentação humana", como uma das principais fontes de proteínas.

Consoante Gaspar et al. (1997), a despeito do elevado status nutricional, o pescado é o alimento de origem animal que mais facilmente se deteriora, sobretudo por apresentar pH próximo da neutralidade, elevada atividade de água nos tecidos, alto teor de nutrientes facilmente utilizáveis pelos micro-organismos, acentuado teor de fosfolipídios e rápida ação destrutiva das enzimas presentes em seus tecidos e vísceras.

Cabe ressaltar, que os agentes biológicos envolvidos na contaminação do pescado incluem bactérias, vírus e parasitas, os quais podem causar moléstias que vão desde uma gastrenterite leve até casos mais sérios, com possível risco de óbito. Essa afirmação parece ser partilhada por Amagliani et al. (2012), quando afirmam que alguns desses patógenos ocorrem naturalmente no ambiente aquático, ao passo que outros podem ser propalados a partir de manipulação inadequada e pela inobservância das medidas higiênicas durante o transporte, manuseio e conservação.

Por outro lado, desde os primórdios, os condimentos são usados nos alimentos, tendo, inclusive, atraído atenção dos povos egípcios, e, posteriormente, do império romano, sendo empregados para as mais diversas funções: embalsamadora, medicamentosa, atenuadora do sabor e do odor dos produtos de origem animal no início da decomposição etc. (Carneiro, 2009).

Hodiernamente, muitos trabalhos de pesquisa demonstram que tanto as ervas in natura quanto as processadas, bem como seus óleos essenciais, podem exercer um importante papel na preparação e no consumo dos alimentos, conforme se depreende do trabalho rea- 
lizado por Inatani (1982), cujos resultados demonstraram as propriedades antimicrobianas e antioxidantes dos condimentos vegetais (ervas aromáticas).

Neste contexto, os temperos e condimentos auferem grande relevância por conferirem sabores agradáveis aos alimentos e por apresentarem substâncias que manifestam propriedades antimicrobianas, antivirais, antioxidantes, antimicóticas, antitoxigênicas, antiparasíticas e inseticidas (Burt, 2004 apud Kruger, 2006).

Concomitantemente, Ozkan \& Erkmen (2001) salientam a preocupação científica em se descobrir novos agentes antimicrobianos, haja vista a assustadora multiplicação de micro-organismos resistentes aos antibacterianos fabricados pela atual indústria farmacêutica.

O mister da troca dos temperos sintéticos pelos produtos naturais existentes nos vários condimentos à nossa disposição também é evidenciada por Deans \& Richtie (1987).

Com ênfase no exposto, este trabalho de revisão foi realizado com o objetivo de analisar as atividades antimicrobianas dos condimentos, temperos e especiarias frente aos agentes toxi-infectivos alimentares padrões do pescado.

\section{MATERIAL E MÉTODOS}

Nesta revisão sistemática de literatura, buscou-se responder as seguintes questões: os condimentos alimentares in natura utilizados no processamento, preparo e/ou no consumo do pescado possuem atividade antimicrobiana seletiva? Quais deles são os mais efetivos nesse desiderato?

A busca por textos publicados até julho de 2016 foi realizada nas bases de dados eletrônicos: LILACS (Latin-American and Caribbean System on Health Sciences Information); MEDLINE (Medical Literature Analysis and Retrieval System Online), SCIELO (Scientific Eletronic Library Online); Scholar Google; Google Acadêmico; CAPES (Comissão de Aperfeiçoamento de Pessoal do Nível Superior); Cochrane Library; Scopus; ScienceDirect e PubMed. Os descritores utilizados no processo de revisão foram selecionados após consulta aos Descritores em Ciências da Saúde, Bireme (DeCS). A busca foi realizada em português, inglês e espanhol, utilizando-se conceitos agrupados em dois blocos: o primeiro com termos relacionados a condimentos, temperos e especiarias ("óleos essenciais", "plantas medicinais", "óleo volátil”, "conservantes de alimentos"); o segundo com termos relacionados ao pescado ("pescado", "medicina veterinária", "antimicrobianos" e "contaminação de alimentos"). Para combinar esses descritores, utilizou-se o operador lógico “OR" dentro de cada bloco e o operador lógico “AND" para combinar os blocos. Utilizou-se a mesma estratégia de busca em todas as bases de dados pesquisadas.

Optou-se por não adotar quaisquer delimitações relacionadas ao tamanho dos dados, linguagem, tipo de estudo ou amostra e em relação ao período de publicação. Todavia, houve a preocupação de aceitar apenas artigos que fizessem menção ao cálculo do tamanho amostral e ao modo de obtenção da amostra estudada. Apesar das bases de pesquisa não possuírem o mesmo período disponível, não houve delimitação do período de publicação dos textos para garantir que todos que pudessem ter algum impacto na conclusão da revisão fossem incluídos. A pesquisa dos textos que compõem esta revisão foi realizada de novembro de 2015 a julho de 2016 e todos os textos selecionados apresentaram cálculo do tamanho amostral.

Os critérios de inclusão foram: artigos originais, revisões sistemáticas e integrativas envolvendo temperos, especiarias e condimentos alimentares in natura e seus possíveis 
efeitos inibitórios sobre a microbiota patógena durante o processamento, preparo e/ou consumo do pescado e de alimentos de origem animal em geral, disponíveis em qualquer idioma. Os critérios de exclusão foram: relatos de caso, atualizações, comunicação breve, estudos repetidos em bases de dados, estudos com baixa qualidade metodológica com escore AMSTAR menor que 6 pontos, estudos que envolvessem ação antimicrobiana de especiarias exóticas à culinária brasileira e artigos com informações incompletas ou que não dispusessem os artigos na íntegra.

A seleção dos artigos foi feita de forma independente e cega por dois avaliadores, que avaliaram os títulos e resumos compilados em banco de dados. Após a seleção dos artigos, houve reunião de consenso a fim de dirimir dúvidas e discordâncias entre os dados coletados pelos avaliadores, com base nos protocolos infracitados.

Artigos duplicados, com resultados idênticos publicados em diferentes revistas, foram checados para exclusão de uma das publicações. Nos casos de duplicidade dos artigos em mais de uma base de dados, manteve-se a versão da base mais abrangente.

Os artigos selecionados foram mapeados em relação ao Autor, Ano, Base de Dados, Tipo de Estudo; Local, Metodologia dos Ensaios; Título Original; Objetivos, Análises Estatísticas e Resultados. Os instrumentos empregados para avaliar a qualidade metodológica dos artigos observacionais incluídos na revisão sistemática foram o "Preferred Reporting Items for Systematic Reviews and Meta-Analyses" (PRISMA) e o "Assessment of Multiple Systematic Reviews" (AMSTAR). De acordo com Moher et al. (2009), o PRISMA é uma lista de verificação específica para estudos de revisão sistemática, contém 27 tópicos e foi desenvolvido para aumentar a qualidade das revisões sistemáticas e metanálises de ensaios clínicos randomizados e artigos não randomizados. O AMSTAR é um instrumento desenvolvido de forma rigorosa e validada para avaliar a qualidade metodológica de revisões sistemáticas (Shea et al., 2009).

A análise dos artigos selecionados foi realizada em duas etapas. A primeira incluiu: ano, base de dados, tipo de estudo; local, metodologia dos ensaios e análises estatísticas. Os resultados foram apresentados de forma descritiva, tabulados e convertidos em amostragem percentual para servirem de base de análise. Na segunda etapa, foi realizada a análise dos objetivos e resultados aferidos nos textos selecionados por meio de estatística descritiva e apresentados expressamente em diagrama de dispersão de dados e gráfico Box Plot (também chamado de box e whisker plot), utilizando-se o programa IBMSPSS Statistics Base 22.0, onde foram identificadas: (a) frequência que os temperos tiveram atividade antimicrobiana comprovada e quais os mais eficientes; (b) frequência dos micro-organismos que sofreram ação anticrobiana nos estudos incluídos e quais os mais susceptíveis a ação dos condimentos (c) locação, dispersão, assimetria, comprimento da cauda e outliers (medidas discrepantes).

\section{RESULTADOS}

A Figura 1 demonstra o fluxograma para o processo de seleção dos textos. Dos 1717 inicialmente identificados em todas as bases, 1179 duplicatas foram excluídas, sendo que: 109 estudos foram excluídos por envolver ação antimicrobiana de especiarias exóticas à culinária brasileira, 87 artigos apresentaram informações incompletas ou não dispuseram os artigos na íntegra, 228 relatos foram excluídos pela baixa qualidade metodológica com escore AMSTAR menor que 6 pontos. Desta forma, 114 textos foram incluídos em síntese qualitativa e qualitativa para a leitura do texto na íntegra. Ainda que 44 artigos tenham 
sido analisados e aprovados segundo os critérios do PRISMA, 23 artigos foram excluídos por serem relatos de caso, atualizações e comunicações breves. Após essa etapa, 21 textos foram considerados elegíveis para a revisão sistemática.

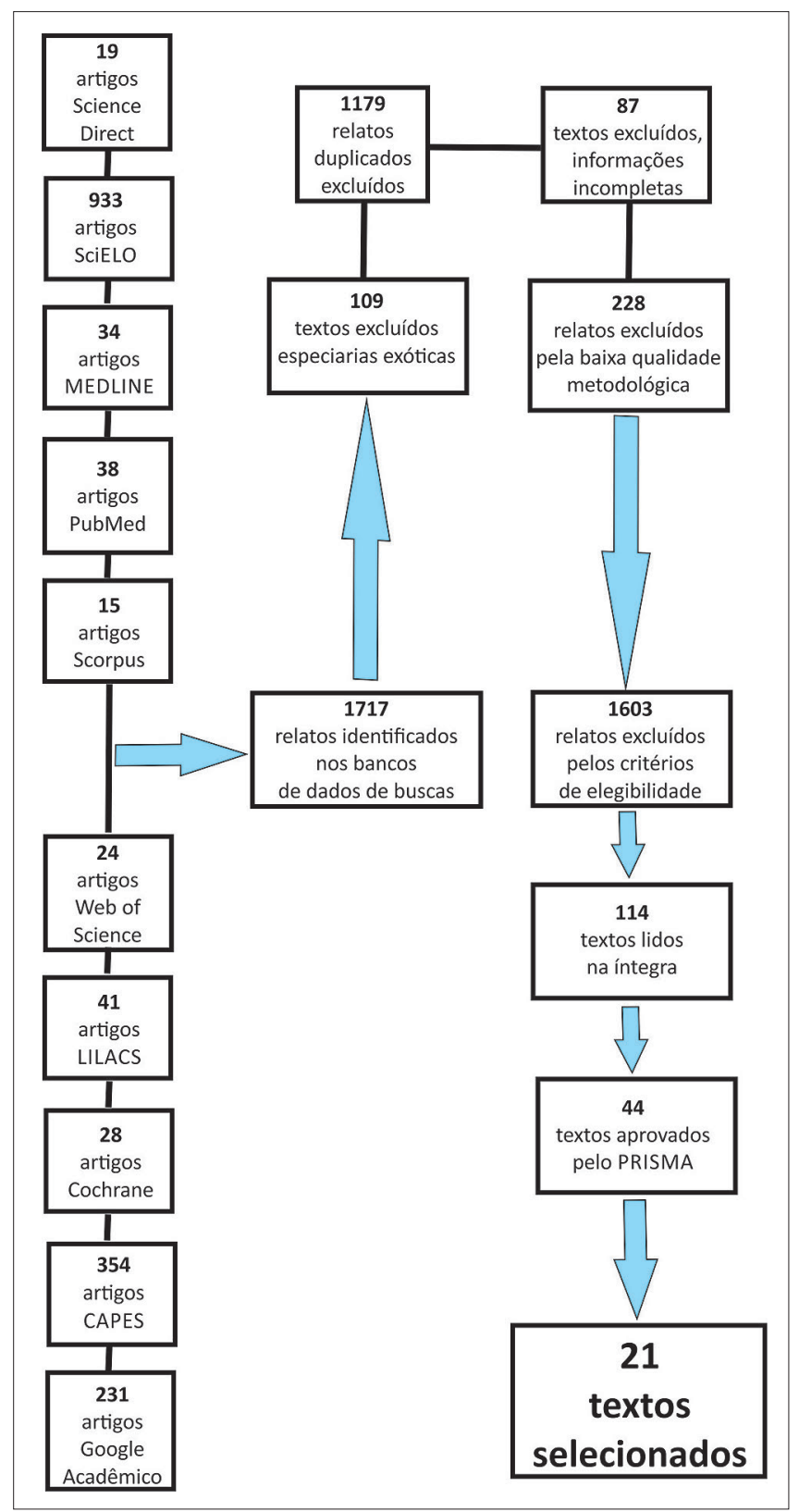

Figura 1 - Fluxograma de seleção dos artigos científicos nas bases de dados. Niterói, RJ, 2016.

Apesar das diferenças metodológicas e amostrais empregadas, todos os artigos que foram selecionados comprovaram os possíveis efeitos inibitórios dos temperos, especiarias e condimentos alimentares in natura sobre a microbiota patógena e/ou deteriorante durante o processamento, preparo e consumo do pescado ou sobre micro-organismos de interesse em alimentos.

Poucos estudos foram publicados no Brasil com o objetivo de avaliar a possibilidade da utilização dos temperos, condimentos e especiarias como opção no combate ao cresci- 
mento de bactérias, leveduras, fungos filamentosos e síntese de toxinas microbianas, bem como na inibição ou retardamento da oxidação especificamente no pescado.

A apresentação da síntese dos textos estão caracterizadas no Quadro 1.

Quadro 1 - Apresentação da síntese dos textos da Revisão Sistemática de Literatura

\begin{tabular}{|c|c|c|c|c|c|}
\hline & $\begin{array}{l}\text { Autor/ Ano/ } \\
\text { Base de Dados / } \\
\text { Tipo de Estudo }\end{array}$ & $\begin{array}{c}\text { Local / } \\
\text { Metodologia dos } \\
\text { Ensaios } \\
\end{array}$ & Título Original & $\begin{array}{l}\text { Objetivos / Análises } \\
\text { Estatísticas }\end{array}$ & Resultados \\
\hline 01 & $\begin{array}{l}\text { Bara et al., } 1998 . \\
\text { CAPES } \\
\text { Artigo Original }\end{array}$ & $\begin{array}{l}\text { Goiânia, GO } \\
\text { Tubos de cultivo. } \\
\text { Contagem de } \\
\text { células viáveis em } \\
\text { placas. }\end{array}$ & $\begin{array}{l}\text { Estudo da atividade } \\
\text { antibacteriana de } \\
\text { plantas medicinais, } \\
\text { aromáticas e } \\
\text { corantes naturais }\end{array}$ & $\begin{array}{l}\text { Investigar a atividade } \\
\text { antimicrobiana o } \\
\text { hortelã, manjericão, } \\
\text { tomilho, alecrim, } \\
\text { pimenta malagueta e } \\
\text { sálvia. } \\
\text { Tabelas, gráficos e } \\
\text { Figuras. }\end{array}$ & $\begin{array}{l}\text { Os resultados encontrados } \\
\text { permitem sugerir que o } \\
\text { alecrim, sálvia e pimenta da } \\
\text { Jamaica constituem-se } \\
\text { antibióticos naturais em face } \\
\text { de Escherichia coli, } \\
\text { Staphylococcus aureus, Listeria } \\
\text { monocytogenes e Yersinia } \\
\text { enterocolitica. }\end{array}$ \\
\hline 02 & $\begin{array}{l}\text { Mejlholm; } \\
\text { Dalgaard, } \\
2002 \\
\text { PubMed }\end{array}$ & $\begin{array}{l}\text { Kongens Lyngby, } \\
\text { Dinamarca } \\
\text { Experimento com } \\
\text { meios líquidos e } \\
\text { ensaios de } \\
\text { armazenamento do } \\
\text { produto }\end{array}$ & $\begin{array}{l}\text { Antimicrobial effect } \\
\text { of essential oils on } \\
\text { the seafood spoilage } \\
\text { micro-organism } \\
\text { Photobacterium } \\
\text { phosphoreum in } \\
\text { liquid media and } \\
\text { fish products }\end{array}$ & $\begin{array}{l}\text { Avaliar o efeito } \\
\text { antimicrobiano de } \\
\text { nove óleos essenciais } \\
\text { (EO) na } \\
\text { Photobacterium } \\
\text { phosphoreum e } \\
\text { determinar o efeito } \\
\text { do óleo de orégano na } \\
\text { vida de prateleira de } \\
\text { filés de bacalhau } \\
\text { embalados sob } \\
\text { atmosfera modificada } \\
\text { ANOVA, teste t de } \\
\text { Sturdent }\end{array}$ & $\begin{array}{l}\text { Os óleos de orégano, louro, } \\
\text { manjerona, sálvia e } \\
\text { manjericão reduziram o } \\
\text { crescimento do Photobacterium } \\
\text { phosphoreum e estenderam o } \\
\text { prazo de validade dos filés, } \\
\text { de bacalhau de } 11 \text { para } 26 \\
\text { dias a } 2^{\circ} \mathrm{C} \text {. }\end{array}$ \\
\hline 03 & $\begin{array}{l}\text { Melo (2003) } \\
\text { SciELO } \\
\text { Artigo Original }\end{array}$ & $\begin{array}{l}\text { Campinas, SP } \\
\text { Espectrofotometria }\end{array}$ & $\begin{array}{l}\text { Atividade } \\
\text { antioxidante de } \\
\text { extratos de coentro } \\
\text { (Coriandrum sativum) }\end{array}$ & $\begin{array}{l}\text { Investigar a atividade } \\
\text { antioxidante de } \\
\text { diferentes extratos de } \\
\text { coentro (Coriandrum } \\
\text { sativum L.) } \\
\\
\text { Analise de variância } \\
\text { (Teste F) e Teste de } \\
\text { Tukey.à significância } \\
\text { de } 5 \% . \text { Software } \\
\text { Minitab "for } \\
\text { Windows". }\end{array}$ & $\begin{array}{l}\text { Os resultados permitem } \\
\text { considerar os extratos aquoso } \\
\text { e etéreo de coentro como } \\
\text { antioxidantes em potencial. }\end{array}$ \\
\hline 04 & $\begin{array}{l}\text { Chalfoun et al., } \\
2004 . \\
\text { SciELO } \\
\text { Artigo Original }\end{array}$ & $\begin{array}{l}\text { Lavras, MG } \\
\text { Contagem de } \\
\text { células viáveis em } \\
\text { placas. }\end{array}$ & $\begin{array}{l}\text { Efeito de } \\
\text { tratamentos com } \\
\text { condimentos em pó } \\
\text { sobre o crescimento } \\
\text { micelial, } \\
\text { esporulação e } \\
\text { produção de } \\
\text { aflatoxinas por } \\
\text { fungos toxigênicos }\end{array}$ & $\begin{array}{l}\text { O efeito de dez } \\
\text { plantas } \\
\text { condimentares em pó } \\
\text { foi avaliado nas } \\
\text { concentrações de 1, 2, } \\
3 \text { e } 4 \%, \text { para observar } \\
\text { o desenvolvimento } \\
\text { micelial e esporulação } \\
\text { de Aspergillus niger e } \\
\text { Eurotium repens. } \\
\text { Tabelas, gráficos e } \\
\text { Figuras. }\end{array}$ & $\begin{array}{l}\text { Alho, tomilho, menta, erva- } \\
\text { doce, orégano e cebola foram, } \\
\text { em ordem decrescente, } \\
\text { antifúngicos promissores. } \\
\text { Louro e manjericão inibiram a } \\
\text { síntese de aflatoxina a partir } \\
\text { da concentração de } 2 \% \text {. }\end{array}$ \\
\hline
\end{tabular}




\begin{tabular}{|c|c|c|c|c|c|}
\hline 05 & $\begin{array}{l}\text { Carvalho et al., } \\
2005 \\
\text { Google } \\
\text { Acadêmico } \\
\text { Artigo Original }\end{array}$ & $\begin{array}{l}\text { Porto Alegre, RS } \\
\text { Diluições seriais } \\
\text { logarítmicas/ } \\
\text { concentrações } \\
\text { bacterianas, } \\
\text { controladas } \\
\text { biometricamente }\end{array}$ & $\begin{array}{l}\text { Atividade } \\
\text { antibacteriana em } \\
\text { plantas com } \\
\text { indicativo } \\
\text { etnográfico } \\
\text { condimentar em } \\
\text { Porto Alegre, RS/ } \\
\text { Brasil. }\end{array}$ & $\begin{array}{l}\text { Determinar a } \\
\text { Intensidade de } \\
\text { Atividade de Inibição } \\
\text { e a Intensidade de } \\
\text { Atividade } \\
\text { de Inativação de } \\
\text { extratos } \\
\text { hidroalcoólicos de } 32 \\
\text { plantas com } \\
\text { indicativo etnográfico } \\
\text { condimentar. } \\
\text { teste de Fisher }\end{array}$ & $\begin{array}{l}\text { As plantas que melhor se } \\
\text { destacaram foram alho, } \\
\text { sálvia, alho-porró, alho-nirá e } \\
\text { pimenta malagueta em face } \\
\text { de Staphylococcus aureus, } \\
\text { Enterococcus faecali, Samonella } \\
\text { Enteritidis, Escherichia coli. }\end{array}$ \\
\hline 06 & $\begin{array}{l}\text { Pereira (2006) } \\
\text { SciELO } \\
\text { Artigo Original }\end{array}$ & $\begin{array}{l}\text { Lavras, MG } \\
\text { Contagem de } \\
\text { células viáveis em } \\
\text { placas }\end{array}$ & $\begin{array}{l}\text { Inibição do } \\
\text { desenvolvimento } \\
\text { fúngico através da } \\
\text { utilização de óleos } \\
\text { essenciais de } \\
\text { condimentos }\end{array}$ & $\begin{array}{l}\text { Avaliar os efeitos } \\
\text { inibitórios, in vitro, de } \\
\text { alecrim, cebola, } \\
\text { manjericão, hortelã, } \\
\text { orégano sobre o } \\
\text { desenvolvimento de } \\
\text { fungos. } \\
\text { Tabelas, gráficos e } \\
\text { Figuras. }\end{array}$ & $\begin{array}{l}\text { O orégano alecrim, menta, } \\
\text { cebola } \\
\text { e manjericão tiveram um } \\
\text { efeito pronunciado no } \\
\text { desenvolvimento dos fungos } \\
\text { Fusarium spp., Aspergillus } \\
\text { ochraceus, Aspergillus flavus, } \\
\text { Aspergillus niger. }\end{array}$ \\
\hline 07 & $\begin{array}{l}\text { Indu et al. (2006) } \\
\text { SciELO } \\
\text { Artigo Original }\end{array}$ & $\begin{array}{l}\text { Suva, Fiji Islands } \\
\text { Difusão de disco } \\
\text { (atividade } \\
\text { antibacteriana dos } \\
\text { óleos essenciais) e } \\
\text { Difusão em poços } \\
\text { (Concentração } \\
\text { Inibitória Mínima - } \\
\text { CIM). }\end{array}$ & $\begin{array}{l}\text { Antimicrobial activity } \\
\text { of some of the south- } \\
\text { Indian spices against } \\
\text { serotypes of } \\
\text { Escherichia coli, } \\
\text { Salmonella, Listeria } \\
\text { monocytogenes and } \\
\text { Aeromonas } \\
\text { hydrophila. }\end{array}$ & $\begin{array}{l}\text { Avaliar a atividade } \\
\text { antimicrobiana de } \\
\text { extratos de alho, noz- } \\
\text { moscada, gengibre, } \\
\text { cebola e pimenta do } \\
\text { reino sobre } 20 \\
\text { sorotipos de } \\
\text { Escherichia coli, } 8 \\
\text { sorotipos de } \\
\text { Salmonella, Listeria } \\
\text { monocytogenes e } \\
\text { Aeromonas hydrophila. } \\
\text { Tabelas, gráficos e } \\
\text { Figuras. }\end{array}$ & $\begin{array}{l}\text { O alho apresentou atividade } \\
\text { antimicrobiana excelente } \\
\text { sobre todos os } \\
\text { microrganismos testados, } \\
\text { exceto L. monocytogenes. A } \\
\text { noz-moscada apresentou boa } \\
\text { atividade antilisteria, embora } \\
\text { a atividade sobre } E \text {. coli e } \\
\text { Salmonella tenha sido } \\
\text { sorotipo-dependente. Tanto } \\
\text { alho como noz-moscada } \\
\text { foram eficientes contra A. } \\
\text { hydrophila. O extrato de } \\
\text { gengibre apresentou } \\
\text { atividade inibitória sobre dois } \\
\text { sorotipos de } E \text {. coli: } 08 \\
\text { (enterotoxigenico) e } 088 \text {. Os } \\
\text { extratos de cebola e pimenta } \\
\text { do reino não apresentaram } \\
\text { nenhuma atividade contra os } \\
\text { microrganismos testados }\end{array}$ \\
\hline 08 & $\begin{array}{l}\text { Trajano et al. } \\
(2009) \\
\text { SciELO }\end{array}$ & $\begin{array}{l}\text { Campinas, SP } \\
\text { Método de difusão } \\
\text { em meio sólido }\end{array}$ & $\begin{array}{l}\text { Propriedade } \\
\text { antibacteriana de } \\
\text { óleos essenciais de } \\
\text { especiarias sobre } \\
\text { bactérias } \\
\text { contaminantes de } \\
\text { alimentos }\end{array}$ & $\begin{array}{l}\text { Analisar as atividades } \\
\text { antibacteriana dos } \\
\text { condimentos: } \\
\text { coentro, canela, } \\
\text { hortelã, manjericão, } \\
\text { louro, manjerona, } \\
\text { pimenta preta, } \\
\text { alecrim, gengibre. } \\
\text { Tabelas, gráficos e } \\
\text { Figuras. }\end{array}$ & $\begin{array}{l}\text { Canela e louro mostraram } \\
\text { uma eficiência na inibição de } \\
\text { todas as cepas bacterianas } \\
\text { ensaiadas. (Bacillus cereus, } \\
\text { Escherichia coli, Listeria } \\
\text { monocytogenes, Pseudomonas } \\
\text { aeruginosa, Staphylococcus } \\
\text { aureus, Yersínia enterocolitica). } \\
\text { Coentro inibiu B. cereus, B. } \\
\text { subtilis, E. coli. S. aureus e Y. } \\
\text { enterocolitica. Cominho inibiu } \\
\text { B. cereus B. subtilis, E. coli, P. } \\
\text { aeruginosa, Y. enterocolitica. } \\
\text { Manjericão inibiu E. coli, P. } \\
\text { aeruginosa, Manjerona inibiu } \\
\text { B. cereus B. subtilis, L. } \\
\text { monocytogenes e S. aureus. } \\
\text { Pimenta-preta inibiu P. } \\
\text { aeruginosa. }\end{array}$ \\
\hline
\end{tabular}


(continuação Quadro 1)

\begin{tabular}{|c|c|c|c|c|c|}
\hline 09 & $\begin{array}{l}\text { Wiest et al., } \\
(2009) \\
\text { SciELO } \\
\text { Artigo Original }\end{array}$ & $\begin{array}{l}\text { Michigan, EUA. } \\
\text { Testes de diluição e } \\
\text { suspensão em } \\
\text { sistema de tubos } \\
\text { múltiplos }\end{array}$ & $\begin{array}{l}\text { Inibição e inativação } \\
\text { in vitro de } \\
\text { Salmonella spp. com } \\
\text { extratos de plantas } \\
\text { com indicativo } \\
\text { etnográfico } \\
\text { medicinal ou } \\
\text { condimentar. }\end{array}$ & $\begin{array}{l}\text { Sintetizar resultados } \\
\text { relativos a } \\
\text { Salmonella spp. frente } \\
\text { a atividade } \\
\text { antibacteriana em } \\
\text { extratos de plantas } \\
\text { com indicativo } \\
\text { etnográfico medicinal, } \\
\text { condimentar ou } \\
\text { aromático. } \\
\text { Análise estatística } \\
\text { descritiva e análise de } \\
\text { variância, com } \\
\text { complementação pelo } \\
\text { teste Duncan e teste t. }\end{array}$ & $\begin{array}{l}\text { Dentre as } 86 \text { plantas com } \\
\text { indicativo etnográfico } \\
\text { medicinal, condimentar ou } \\
\text { aromático acessadas, } 50 \\
\text { apresentaram alguma } \\
\text { atividade antissalmonela. } \\
\text { Dentre as plantas acessadas, } \\
\text { nas condições dos diferentes } \\
\text { experimentos, por atingirem } \\
\text { valores arbitrários atribuídos } \\
\text { em grau máximo, } 8 \text {, tanto em } \\
\text { IINIB como em IINAB sobre } \\
\text { Salmonella spp., destacam-se } \\
\text { alho-porró, alho-nirá, } \\
\text { pimenta-malagueta, orégano, } \\
\text { sálvia. }\end{array}$ \\
\hline 10 & $\begin{array}{l}\text { Costa et al., } \\
(2009) \\
\text { SciELO } \\
\text { Artigo Original }\end{array}$ & $\begin{array}{l}\text { João Pessoa, PB } \\
\text { Difusão em meio } \\
\text { sólido } \\
\text { microdiluição e } \\
\text { Contagem de } \\
\text { células viáveis em } \\
\text { placas }\end{array}$ & $\begin{array}{l}\text { Atividade } \\
\text { antibacteriana do } \\
\text { óleo essencial de } \\
\text { Origanum vulgare L. } \\
\text { (Lamiaceae) contra } \\
\text { bactérias } \\
\text { multiressistentes } \\
\text { isoladas de } \\
\text { pacientes } \\
\text { nosocomial. }\end{array}$ & $\begin{array}{l}\text { Determinar a } \\
\text { atividade } \\
\text { antimicrobiana do } \\
\text { orégano contra } \\
\text { bactérias } \\
\text { multirresistentes. } \\
\text { Tabelas, gráficos e } \\
\text { Figuras. }\end{array}$ & $\begin{array}{l}\text { O óleo essencial de orégano } \\
\text { apresentou atividade } \\
\text { bactericida sobre } \\
\text { Staphylococcus aureus, } \\
\text { Escherichia coli, Pseudomonas } \\
\text { aeruginosa }\end{array}$ \\
\hline 11 & $\begin{array}{l}\text { Araújo et al. } \\
(2009) \\
\text { Google } \\
\text { Acadêmico } \\
\text { Artigo Original }\end{array}$ & $\begin{array}{l}\text { Diluição em } \\
\text { Sistema de tubos } \\
\text { múltiplos sobre } \\
\text { inócuos } \\
\text { padronizados. }\end{array}$ & $\begin{array}{l}\text { Atividade } \\
\text { antibacteriana in } \\
\text { vitro de extratos de } \\
\text { alho nirá (Allium } \\
\text { tuberosum Rottler ex } \\
\text { Spreng.) }\end{array}$ & $\begin{array}{l}\text { Demonstrar a } \\
\text { influência da } \\
\text { condimentação sobre } \\
\text { a Validade Preditiva } \\
\text { dos Resultados } \\
\text { Negativos do } \\
\text { diagnóstico de } \\
\text { bactérias } \\
\text { transmissíveis por } \\
\text { alimentos, através do } \\
\text { uso de alho -nirá. } \\
\text { Análise estatística } \\
\text { descritiva e análise de } \\
\text { variância, } \\
\text { complementado pelo } \\
\text { teste de Tukey. }\end{array}$ & $\begin{array}{l}\text { Os testes revelaram atividade } \\
\text { antibacteriana seletiva sobre } \\
\text { os diferentes inóculos Gram- } \\
\text { negativos, que atingiram } \\
\text { inibição e inativação máximas } \\
\text { e permanentes para Salmonella } \\
\text { enteritidis após } 48 \mathrm{~h} \text { e para } \\
\text { Escherichia coli, após } 72 \mathrm{~h} \text {. As } \\
\text { bactérias Gram-positivas, } \\
\text { Staphylococcus e Enterococcus, } \\
\text { apresentaram resistência total } \\
\text { frente aos extratos etanólicos }\end{array}$ \\
\hline 12 & $\begin{array}{l}\text { Resende et al. } \\
(2009) \\
\text { CAPES }\end{array}$ & $\begin{array}{l}\text { Campinas, SP. } \\
\text { Métodos de } \\
\text { difusão em disco e } \\
\text { microdiluição em } \\
\text { caldo }\end{array}$ & $\begin{array}{l}\text { Atividade de óleos } \\
\text { essenciais de plantas } \\
\text { utilizadas na } \\
\text { Culinária sobre } \\
\text { bactérias } \\
\text { patogênicas ou } \\
\text { Deteriorantes de } \\
\text { alimentos. }\end{array}$ & $\begin{array}{l}\text { Determinar a } \\
\text { atividade } \\
\text { antibacteriana de } \\
\text { óleos essenciais do } \\
\text { gengibre, cominho, } \\
\text { açafrão, coentro, } \\
\text { tomilho, manjericão, } \\
\text { Tabelas, gráficos e } \\
\text { Figuras. }\end{array}$ & $\begin{array}{l}\text { Foi observado no teste de } \\
\text { difusão que o óleo essencial } \\
\text { de tomilho foi o que teve } \\
\text { melhor atividade seguido } \\
\text { pelo manjericão em face dos } \\
\text { microrganismos utilizados } \\
\text { nos testes } \\
\text { de susceptibilidade: } \\
\text { Escherichia, Bacilus cereus, } \\
\text { Salmonella, Escherichia coli, } \\
\text { Staphylococcus aureus }\end{array}$ \\
\hline
\end{tabular}


(continuação Quadro 1)

\begin{tabular}{|c|c|c|c|c|c|}
\hline 13 & $\begin{array}{l}\text { Silva et al., } 2010 \\
\text { SciELO } \\
\text { Artigo Original }\end{array}$ & $\begin{array}{l}\text { Campinas, SP. } \\
\text { Cromatografia } \\
\text { gasosa acoplada ao } \\
\text { espectrômetro de } \\
\text { massas. A } \\
\text { atividade inibitória } \\
\text { foi avaliada pela } \\
\text { técnica de difusão } \\
\text { em poços. }\end{array}$ & $\begin{array}{l}\text { Óleo essencial de } \\
\text { orégano: } \\
\text { interferência da } \\
\text { composição química } \\
\text { na atividade frente a } \\
\text { Salmonella } \\
\text { Enteritidis. }\end{array}$ & $\begin{array}{l}\text { Avaliar a } \\
\text { interferência dos } \\
\text { compostos fenólicos } \\
\text { de óleo essencial de } \\
\text { orégano na atividade } \\
\text { inibitória frente à } \\
\text { Salmonella } \\
\text { Enteritidis. } \\
\text { Análise de variância } \\
\text { (ANOVA); teste de } \\
\text { médias pelo } \\
\text { programa Sisvar para } \\
\text { Windows versão } 4.0 \\
\text { (p < 0,05); teste de } \\
\text { Tukey. }\end{array}$ & $\begin{array}{l}\text { Comprovou-se que a } \\
\text { multiplicação da Salmonella } \\
\text { Enteritidis in vitro pode ser } \\
\text { inibida por OEO. Neste } \\
\text { sentido, os óleos essenciais } \\
\text { que possuem p-cimeno e } \\
\text { y-terpineno, além de } \\
\text { carvacrol, podem ter o seu } \\
\text { efeito antimicrobiano } \\
\text { potencializado }\end{array}$ \\
\hline 14 & $\begin{array}{l}\text { Santos et al., } \\
2011 \\
\text { Scopus }\end{array}$ & $\begin{array}{l}\text { Londrina, PR. } \\
\text { Difusão de disco } \\
\text { (atividade } \\
\text { antibacteriana dos } \\
\text { óleos essenciais) e } \\
\text { Difusão em poços } \\
\text { (Concentração } \\
\text { Inibitória Mínima - } \\
\text { CIM). }\end{array}$ & $\begin{array}{l}\text { Atividade } \\
\text { antimicrobiana in } \\
\text { vitro dos óleos } \\
\text { essenciais de } \\
\text { orégano, alho, cravo } \\
\text { e limão sobre } \\
\text { bactérias } \\
\text { patogênicas isoladas } \\
\text { de vôngole }\end{array}$ & $\begin{array}{l}\text { Avaliar a atividade } \\
\text { antibacteriana dos } \\
\text { óleos essenciais de } \\
\text { alho, cravo-da-índia, } \\
\text { orégano e limão } \\
\text { siciliano sobre cepas } \\
\text { de Staphylococcus } \\
\text { aureus e Escherichia } \\
\text { coli isoladas do } \\
\text { bivalve Anomalocardia } \\
\text { brasiliana e cepas } \\
\text { padrão de Escherichia } \\
\text { coli, Staphylococcus } \\
\text { aureus e Salmonella } \\
\text { cholerasuis. } \\
\text { ANOVA, teste de } \\
\text { Tukey a 5\% }\end{array}$ & $\begin{array}{l}\text { Observou-se que o óleo } \\
\text { essencial de alho apresentou } \\
\text { atividade antibacteriana } \\
\text { frente o Staphylococcus aureus } \\
\text { e a Salmonella. cholerasuis; já os } \\
\text { óleos de cravo e orégano } \\
\text { apresentaram atividade frente } \\
\text { a todas as bactérias } \\
\text { analisadas. O óleo essencial } \\
\text { de limão não demonstrou } \\
\text { atividade antibacteriana. } \\
\text { Os resultados demonstraram } \\
\text { a maior eficácia do óleo } \\
\text { essencial de orégano em } \\
\text { relação ao de cravo sobre } \\
\text { todas as cepas analisadas. } \\
\text { Verificou-se que a adição do } \\
\text { óleo essencial reduziu a } \\
\text { população de Salmonella spp } \\
\text { em } 5,6 \text { ciclos logarítmicos nas } \\
\text { amostras de vôngole } \\
\text { artificialmente inoculados. A } \\
\text { ação do óleo essencial de } \\
\text { cravo garantiu a inibição de } \\
\text { Salmonella, E. coli e S. aureus, } \\
\text { por no mínimo dois dias, sob } \\
\text { refrigeração. }\end{array}$ \\
\hline 15 & $\begin{array}{l}\text { Larosa et al., } \\
2012 . \\
\text { Capes } \\
\text { Artigo Original. }\end{array}$ & $\begin{array}{l}\text { Araraquara, SP } \\
\text { Contagem de } \\
\text { células viáveis em } \\
\text { placas }\end{array}$ & $\begin{array}{l}\text { Elaboração de } \\
\text { produto cárneo de } \\
\text { tilápia com } \\
\text { antioxidantes } \\
\text { visando sua } \\
\text { utilização como } \\
\text { recheio ou } \\
\text { acompanhamento } \\
\text { da refeição }\end{array}$ & $\begin{array}{l}\text { Desenvolver um } \\
\text { produto cárneo de } \\
\text { tilápia com } \\
\text { antioxidantes } \\
\text { naturais (alecrim, } \\
\text { orégano, sálvia) } \\
\text { visando sua utilização } \\
\text { como recheio ou } \\
\text { acompanhamento da } \\
\text { refeição. } \\
\text { ANOVA, Teste de } \\
\text { Tukey a 5\%, Software } \\
\text { AgroEstat. }\end{array}$ & $\begin{array}{l}\text { Os resultados obtidos } \\
\text { indicaram que não foram } \\
\text { detectadas as bactérias } \\
\text { patogênicas Salmonella e } \\
\text { estafilococos nos produtos à } \\
\text { base de pescado, constatou-se } \\
\text { também grande inibição de } \\
\text { microrganismos aeróbios } \\
\text { psicrotróficos (Pseudomonas, } \\
\text { Alcaligenes, Flavobacterium, } \\
\text { Micrococcus, Aeromonas, } \\
\text { Listeria). }\end{array}$ \\
\hline
\end{tabular}


(continuação Quadro 1)

\begin{tabular}{|c|c|c|c|c|c|}
\hline 16 & $\begin{array}{l}\text { Del Ré; Jorge, } \\
2012 \\
\text { SciELO } \\
\text { Artigo de } \\
\text { Revisão }\end{array}$ & $\begin{array}{l}\text { Botucatu, SP } \\
\text { Revisão de } \\
\text { Literatura }\end{array}$ & $\begin{array}{l}\text { Especiarias como } \\
\text { antioxidantes } \\
\text { naturais: aplicações } \\
\text { em alimentos e } \\
\text { implicação na saúde }\end{array}$ & $\begin{array}{l}\text { Avaliar a atividade } \\
\text { antioxidante da } \\
\text { alecrim, hortelã, } \\
\text { manjericão, orégano, } \\
\text { salsa, tomilho sobre a } \\
\text { estabilidade oxidativa } \\
\text { de alguns alimentos. } \\
\text { Tabelas, gráficos e } \\
\text { Figuras }\end{array}$ & $\begin{array}{l}\text { Os óleos essenciais da salsa, } \\
\text { orégano, alecrim e hortelã } \\
\text { foram as ervas mais eficientes } \\
\text { na prevenção da oxidação. }\end{array}$ \\
\hline 17 & $\begin{array}{l}\text { Gandra et al., } \\
2013 . \\
\text { SciELO } \\
\text { Artigo Original }\end{array}$ & $\begin{array}{l}\text { Pelotas, RS } \\
\text { Contagem de } \\
\text { células viáveis em } \\
\text { placas }\end{array}$ & $\begin{array}{l}\text { Potencial } \\
\text { antimicrobiano e } \\
\text { antioxidante de } \\
\text { extratos vegetais de } \\
\text { alecrim, erva doce, } \\
\text { estragão e orégano }\end{array}$ & $\begin{array}{l}\text { Avaliar a atividade } \\
\text { antibacteriana e } \\
\text { antioxidante de } \\
\text { extratos vegetais de } \\
\text { estragão, orégano, } \\
\text { erva doce e alecrim. } \\
\text { Tabelas, gráficos e } \\
\text { Figuras. }\end{array}$ & $\begin{array}{l}\text { Os extratos de orégano e } \\
\text { alecrim apresentaram } \\
\text { atividade antimicrobiana } \\
\text { frente às culturas de } S \text {. aureus } \\
e \text { E. coli, e valores de } \\
\text { compostos fenólicos totais e } \\
\text { capacidade antioxidante } \\
\text { superiores aos encontrados } \\
\text { no extrato de erva doce e de } \\
\text { estragão, permitindo afirmar } \\
\text { que os mesmos apresentam } \\
\text { potencial antimicrobiano e } \\
\text { antioxidante. }\end{array}$ \\
\hline 18 & $\begin{array}{l}\text { Pereira, et al., } \\
2014 . \\
\text { SciELO } \\
\text { Artigo Original }\end{array}$ & $\begin{array}{l}\text { Santa Maria, RS. } \\
\text { Técnica de diluição } \\
\text { em placas e } \\
\text { Contagem de } \\
\text { células viáveis em } \\
\text { placas }\end{array}$ & $\begin{array}{l}\text { Inativação } \\
\text { termoquímica de } \\
\text { Escherichia coli, } \\
\text { Staphylococcus aureus } \\
\text { e Salmonella enterica } \\
\text { Enteritidis por óleos } \\
\text { essenciais }\end{array}$ & $\begin{array}{l}\text { Avaliar a atividade } \\
\text { antimicrobiana e a } \\
\text { curva de morte } \\
\text { termoquímica de } \\
\text { soluções desinfetantes } \\
\text { de óleos essenciais } \\
\text { sobre Escherichia coli, } \\
\text { Staphylococcus aureus e } \\
\text { Salmonella enteritidis } \\
\text { Analise estatística de } \\
\text { variância, teste de } \\
\text { Tukey à 5\% }\end{array}$ & $\begin{array}{l}\text { Observou-se uma maior } \\
\text { eficiência antibacteriana para } \\
\text { o óleo essencial de tomilho } \\
\text { em face de Escherichia coli, } \\
\text { Salmonella enteritidis., } \\
\text { Staphylococcus aureus }\end{array}$ \\
\hline 19 & $\begin{array}{l}\text { Brilhante et al., } \\
2015 . \\
\text { ScienceDirect } \\
\text { Artigo Original }\end{array}$ & $\begin{array}{l}\text { Fortaleza, CE } \\
\text { Tubos de cultivo. } \\
\text { Contagem de } \\
\text { células viáveis em } \\
\text { placas }\end{array}$ & $\begin{array}{l}\text { Vibrio spp. from } \\
\text { Macrobrachium } \\
\text { amazonicum prawn } \\
\text { farming are } \\
\text { inhibited by Moringa } \\
\text { oleifera extracts. }\end{array}$ & $\begin{array}{l}\text { Investigar o potencial } \\
\text { antimicrobiano in } \\
\text { vitro de extratos de } \\
\text { caule, folhas, flores, } \\
\text { vagens e sementes de } \\
\text { Moringa oleifera em } \\
\text { face de Vibrio spp. } \\
\text { presente no camarão } \\
\text { Macrobrachium } \\
\text { amazonicum. } \\
\text { Coeficiente de } \\
\text { correlação linear (r) }\end{array}$ & $\begin{array}{l}\text { O melhor resultado foi obtido } \\
\text { com o extrato etanólico de } \\
\text { vagens, que inibiu três } \\
\text { estirpes do Vibrio cholerae, } \\
\text { Vibrio vulnificus, mimicus } \\
\text { Vibrio mimicus.. }\end{array}$ \\
\hline
\end{tabular}




\begin{tabular}{|c|c|c|c|c|c|}
\hline 20 & $\begin{array}{l}\text { Araújo et al., } \\
2015 . \\
\text { LILACS }\end{array}$ & $\begin{array}{l}\text { Curitiba, PR. } \\
\text { Cromatografia } \\
\text { gasosa acoplada à } \\
\text { espectrometria de } \\
\text { massas } \\
\text { (determinação } \\
\text { composição } \\
\text { química óleo } \\
\text { essencial) } \\
\text { Contagem de } \\
\text { células viáveis em } \\
\text { placas (contagem } \\
\text { de Escherichia } \\
\text { coli). }\end{array}$ & $\begin{array}{l}\text { Composição } \\
\text { química e } \\
\text { susceptibilidade do } \\
\text { óleo essencial } \\
\text { de orégano } \\
\text { (Origanum vulgare } \\
\text { L., família } \\
\text { lamiaceae) frente } \\
\text { À cepas de } \\
\text { Escherichia coli, } \\
\text { Staphylococcus aureus } \\
\text { e Salmonella } \\
\text { choleraesuis }\end{array}$ & $\begin{array}{l}\text { Determinar } \\
\text { a composição química } \\
\text { e avaliar a atividade } \\
\text { antibacteriana do } \\
\text { óleo essencial de } \\
\text { orégano frente às } \\
\text { cepas de Escherichia } \\
\text { coli, Staphylococcus } \\
\text { aureus e Salmonella } \\
\text { choleraesuis. }\end{array}$ & $\begin{array}{l}\text { Com base nos resultados } \\
\text { obtidos conclui-se que o óleo } \\
\text { essencial de orégano } \\
\text { apresentou uma excelente } \\
\text { ação antibacteriana sobre as } \\
\text { cepas de Escherichia coli, } \\
\text { Staphylococcus aureuse } \\
\text { Salmonella choleraesuis, tendo } \\
\text { como componentes químicos } \\
\text { majoritários o 4-terpineol e } \\
\text { timol. }\end{array}$ \\
\hline 21 & $\begin{array}{l}\text { Radaelli et al., } \\
2016 . \\
\text { PubMed }\end{array}$ & $\begin{array}{l}\text { Lajeado, RS } \\
\text { Cromatografia } \\
\text { gasosa acoplada a } \\
\text { espectrometria de } \\
\text { massas. Contagem } \\
\text { de células viáveis } \\
\text { em placas }\end{array}$ & $\begin{array}{l}\text { Antimicrobial } \\
\text { activities of six } \\
\text { essential oils } \\
\text { commonly used as } \\
\text { condiments in Brazil } \\
\text { against Clostridium } \\
\text { perfringens. }\end{array}$ & $\begin{array}{l}\text { Determinar atividade } \\
\text { antimicrobiana de } \\
\text { óleos essenciais de } \\
\text { manjericão, alecrim, } \\
\text { hortelã- pimenta, } \\
\text { tomilho, } \\
\text { Tabelas, gráficos e } \\
\text { Figuras. }\end{array}$ & $\begin{array}{l}\text { Os óleos essenciais de } \\
\text { manjericão, alecrim, } \\
\text { manjerona, hortelã-pimenta e } \\
\text { tomilho apresentaram } \\
\text { atividades antimicrobianas in } \\
\text { vitro contra Clostridium } \\
\text { perfringens. A utilização de } \\
\text { óleos essenciais a partir de } \\
\text { comumente empregues } \\
\text { especiarias claramente oferece } \\
\text { uma alternativa aos } \\
\text { conservantes químicos no } \\
\text { controle e inativação de } \\
\text { agentes patogénicos nos } \\
\text { alimentos }\end{array}$ \\
\hline
\end{tabular}

Os artigos selecionados nesta revisão foram publicados entre os anos de 1998 e 2016. Em relação às bases de dados, observa-se que 11 artigos (52,3\%) foram publicados na base SciELO, três (14,3\%) no CAPES, dois (9,5\%) no PUBMED, dois (9,5\%) no Google Acadêmico, um $(4,7 \%)$ no Scopus, um $(4,7 \%)$ no ScienceDirect e um $(4,7 \%)$ no LILACS. Nenhum artigo foi selecionado das bases Web of Science, MEDLINE, Cochrane Library.

Quanto aos locais e aos quantitativos dos estudos selecionados, percebe-se que seis $(28,5 \%)$ de São Paulo; cinco $(23,8 \%)$ do Rio Grande do Sul; dois $(9,5 \%)$ do Paraná, dois $(9,5 \%)$ de Minas Gerais; um $(4,7 \%)$ da Paraíba; um $(4,7 \%)$ de Goiás e um $(4,7 \%)$ do Ceará. Dentre os internacionais, um (4,7\%) das Ilhas Fiji; um (4,7\%) da Dinamarca e um $(4,7 \%)$ dos EUA.

Em relação à análise dos dados, os testes estatísticos descritivos e inferenciais mais utilizados foram: em seis artigos $(22,2 \%)$ teste de Turkey; em quatro $(14,8 \%)$ ANOVA; em dois $(8,1 \%)$ teste $t$ de Student; em um (3,7\%) teste de Fisher; em um $(3,7 \%)$ teste Duncan; em um $(3,7 \%)$ coeficiente de correlação linear e um $(3,7 \%)$ Coeficiente Linear. Cabe ressaltar que, pela natureza da maioria dos estudos, não foram utilizados testes estatísticos inferenciais em $11(40,7 \%)$ pesquisas, e sim, análises descritivas com representação dos dados através de gráficos, tabelas e Figuras. 
No que diz respeito às metodologias dos ensaios empregados pelos autores dos textos apurados, dois deles $(7,1 \%)$ utilizaram difusão em meio sólido; dois $(7,1 \%)$ microdiluição; dez (35,7\%) contagem de células viáveis em placas; três (10,7\%) cromatografia gasosa acoplada à espectrometria de massas; três (10,7\%) difusão em disco; três (10,7\%) difusão em poços; um $(3,5 \%)$ difusão em meio líquido; dois $(7,1 \%)$ diluição e suspensão em tubos múltiplos; um (3,5\%) espectrofotometria e um (3,5\%) diluições seriais logarítmicas.

Todos os artigos presentes na revisão trabalharam com temperos, condimentos e especiarias presentes na culinária na brasileira, os quais foram pesquisados e estão dispostos no Quadro 2, a saber: coentro; canela; hortelã; manjericão; louro; manjerona; pimenta preta; alecrim; gengibre; sálvia; orégano; alho; cravo-da-Índia; limão siciliano; estragão; erva-doce; cebola; noz-moscada; pimenta-do-reino; tomilho; pimenta-de-macaco; salsa; pimenta malagueta; alho-poró; alho-nirá; menta; cominho e acácia-branca.

Observa-se que entre os 27 temperos pesquisados, aqueles que os autores concluíram serem os mais eficientes quanto às suas atividades antimicrobianas foram, em ordem decrescente: Orégano (Mejlholm, 2002; Chalfoun et al., 2004; Pereira, 2006; Costa et al, 2009; Wiest et al., 2009; Silva et al., 2010; Santos et al., 2011; Larosa et al., 2012; Del Ré \& Jorge, 2012, Araújo et al., 2015); alecrim (Bara, 1998; Trajano et al., 2009; Gandra, 2013; Larosa et al., 2012; Del Ré \& jorge, 2012; Gandra, 2013; Radaelli et al. 2016); sálvia (Bara et al., 1998; Mejlholm \& Dalgaard, 2002; Carvalho et al., 2005; Wiest et al., 2009; Larosa et al., 2012); manjericão (Mejlholm \& Dalgaard, 2002; Chalfoun et al., 2004; Pereira 2006; Trajano, 2009; Resende et al., 2009; Radaelli et al., 2016); tomilho (Chalfoun et al., 2004; Resende et al., 2009; Pereira, et al., 2014; Radaelli, 2016); louro (Mejlholm \& Dalgaard, 2002; Trajano et al., 2009); alho (Carvalho, 2005; Wiest et al., 2009; Araújo et al., 2009); pimenta-malagueta (Wiest et al., 2009; Carvalho et al., 2005).

Três artigos descreveram também as atividades antioxidantes dos condimentos: orégano; salsa; alecrim e coentro (Melo, 2003; Del Ré \& Jorge, 2012; Gandra et al., 2013).

O extrato etanólico das vagens de Moringa oleifera inibiu três estirpes de Vibrios: Vibrio cholerae, Vibrio vulnificus, mimicus Vibrio mimicus

Quadro 2 - Frequência em que os temperos, condimentos e especiarias tiveram sua efetividade antimicrobiana ou antioxidante confirmada nos textos selecionados. Niterói, RJ, 2016.

\begin{tabular}{|c|c|c|}
\hline Variáveis & $\mathbf{N}$ & $\%$ \\
\hline Coentro & 5 & 2,7 \\
\hline Canela & 7 & 3,8 \\
\hline Hortelã (menta) & 6 & 3,3 \\
\hline Manjericão & 13 & 7,2 \\
\hline Louro & 9 & 5,0 \\
\hline Manjerona & 6 & 3,3 \\
\hline Pimenta preta & 1 & 0,9 \\
\hline Alecrim & 19 & 10,5 \\
\hline Gengibre & 1 & 0,9 \\
\hline Sálvia & 18 & 10,0 \\
\hline Orégano & 31 & 17,2 \\
\hline Alho & 8 & 4,4 \\
\hline Cravo-da-Índia & 1 & 0,9 \\
\hline Limão siciliano & 0 & 0,0 \\
\hline Estragão & 2 & 1,1 \\
\hline Erva-doce & 2 & 1,1 \\
\hline Cebola & 6 & 3,3 \\
\hline Noz-moscada & 4 & 2,2 \\
\hline Pimenta-do-Reino & 0 & 0,0 \\
\hline Tomilho & 10 & 5,5 \\
\hline Pimenta-de-macaco & 3 & 1,6 \\
\hline Salsa & 0 & 0,0 \\
\hline Pimenta-malagueta & 8 & 4,4 \\
\hline Alho-poró & 5 & 2,7 \\
\hline Alho-nirá & 7 & 3,8 \\
\hline Cominho & 5 & 2,7 \\
\hline Acácia-branca (Moringa) & 3 & 1,6 \\
\hline Total & 180 & 100,0 \\
\hline
\end{tabular}

Fonte: Elaboração e pesquisa realizadas pelo autor (2016).

(Brilhante et al., 2015)

Santos et al. (2011) concluíram não haver atividade antibacteriana do limão siciliano em Staphylococcus aureus, Escherichia colie Salmonella cholerasuis. Indu (2006) não encontrou nenhuma atividade contra Escherichia coli, Salmonella, Listeria monocytogenes e Aeromonas hydrophila na cebola e na pimenta do reino.

O Quadro 3 apresenta todos os micro-organismos de interesse em alimentos e que sofreram ação antimicrobiana dos temperos estudados nos textos escolhidos, são eles: 
Bacillus cereus; Bacillus subtilis; Escherichia coli; Listeria monocytogenes, Pseudomonas aeruginosa, Staphylococcus aureus, Yersínia enterocolítica,; Photobacterium phosphoreum; Enterococcus faecali, Clostridium perfringens, Alcaligenes, Flavobacterium, Micrococcus, Aeromonas hydrophila; Salmonella cholerasuis; Samonella enteritidis, Salmonella spp; Vibrio cholerae; Vibrio vulnificus, mimicus; Vibrio mimicus; Fusarium spp, Candida albicans, Aspergillus ochraceus, Aspergillus flavus, Aspergillus niger; Eurotium (aspergillus) repens.

Considerando-se as amostras de todos os estudos, infere-se que os micro-organismos mais estudados pelos autores foram, em ordem decrescente: Escherichia coli (Bara, 1998; Carvalho, 2005; Indu, 2006; Trajano et al., 2009; Costa et al., 2009; Resende et al., 2009; Araújo et al., 2009; Santos et al., 2011; Gandra, 2013; Pereira et al., 2014; Araújo et al., 2015); Staphylococcus aureus (Bara, 1998; Carvalho et al., 2005; Trajano et al., 2009; Resende et al., 2009; Araújo et al., 2009; Costa et al., 2009; Alves, 2010; Santos et al., 2011; Gandra et al., 2013; Pereira, et al., 2014; Araújo et al., 2015); Salmonella spp (Indu et al., 2006; Resende et al., 2009; Wiest et al., 2009; Larosa et al., 2012); Listeria monocytogenes (Bara, 1998; Indu et al., 2006); Trajano et al., 2009; Larosa et al., 2012); Bacillus cereus (Trajano et al., 2009; Resende et al.,2009).

Os resultados da Figura 2 também permitem inferir que cinco temperos (orégano, alecrim, sálvia, manjericão e tomilho) apresentam composição química mais rica em compostos com potencial antimicrobiano, levantando-se a possibilidade de sua utilização na aplicação de formulações alimentares de pescado desenvolvidos para a indústria de alimentos, bem como no seu preparo e/ou consumo.

Ao se traçar uma linha horizontal na altura do 10 (eixo y), ver-se-á que os pontos

Quadro 3 - Frequência com que os micro-organismos de interesse em alimentos sofreram atividade antimicrobiana em face dos condimentos, temperos e especiarias nos experimentos dos textos selecionados. Niterói, RJ, 2016.

\begin{tabular}{lcc}
\hline \multicolumn{1}{c}{ Variáveis } & N & $\%$ \\
\hline Bacillus cereus & 8 & 4,5 \\
Bacillus subtilis & 3 & 1,7 \\
Escherichia coli & 30 & 17,2 \\
Listeria monocytogenes & 13 & 7,4 \\
Pseudomonas aeruginosa & 7 & 4,0 \\
Staphylococcus aureus & 26 & 14,9 \\
Yersinia enterocolitica & 7 & 4,0 \\
Photobacterium phosphoreum & 4 & 2,2 \\
Enterococcus faecali & 4 & 2,2 \\
Clostridium perfringens & 4 & 2,2 \\
Alcaligenes & 3 & 1,7 \\
Flavobacterium & 3 & 1,7 \\
Micrococcus & 3 & 1,7 \\
Aeromonas hydrophila & 7 & 4,0 \\
Salmonella cholerasuis & 3 & 1,7 \\
Samonella enteritidis & 5 & 2,8 \\
Salmonella spp. & 17 & 9,7 \\
Vibrio navarrensis & 1 & 0,5 \\
Vibrio brasiliensis & 1 & 0,5 \\
Vibrio parahaemolyticus & 1 & 0,5 \\
Fusarium spp & 5 & 2,8 \\
Candida albicans & 1 & 0,5 \\
Aspergillus ochraceus & 4 & 2,2 \\
Aspergillus flavus & 4 & 2,2 \\
Aspergillus niger & 7 & 4,0 \\
Eurotium repens & 4 & 4,0 \\
& & \\
Total & 174 & 100,0 \\
\hline Fonte: Elaboraçã e pesqua & & \\
& &
\end{tabular}

Fonte: Elaboração e pesquisa realizadas pelo autor, IBM SPSS Statistics Base 22.0, 2016. estão dispersos principalmente na área abaixo e a mediana do "Box Plot" (Figura 3) está perto da metade dessa área. Acima do valor 10 indica os temperos com mais efetividade sobre os micro-organismos registrados. Valores mais próximos ao zero são os temperos com 2, 1 ou nenhum micro-organismo registrado. A pimenta que tem o valor tomado como indicativo dessa dispersão é a pimenta de macaco.

O centro da distribuição é indicado pela linha da mediana. A altura do retângulo é definida pelos quartis Q1 e Q3 e a dispersão é representada pela altura do retângulo (Q3 - Q1).

A linha que secciona o retângulo representa o valor da mediana (ou Q2). As semirretas ligam respectivamente os quartis Q1 e Q3 ao valor mínimo e ao máximo do conjunto de dados. O retângulo contém $50 \%$ dos valores do conjunto de dados. 


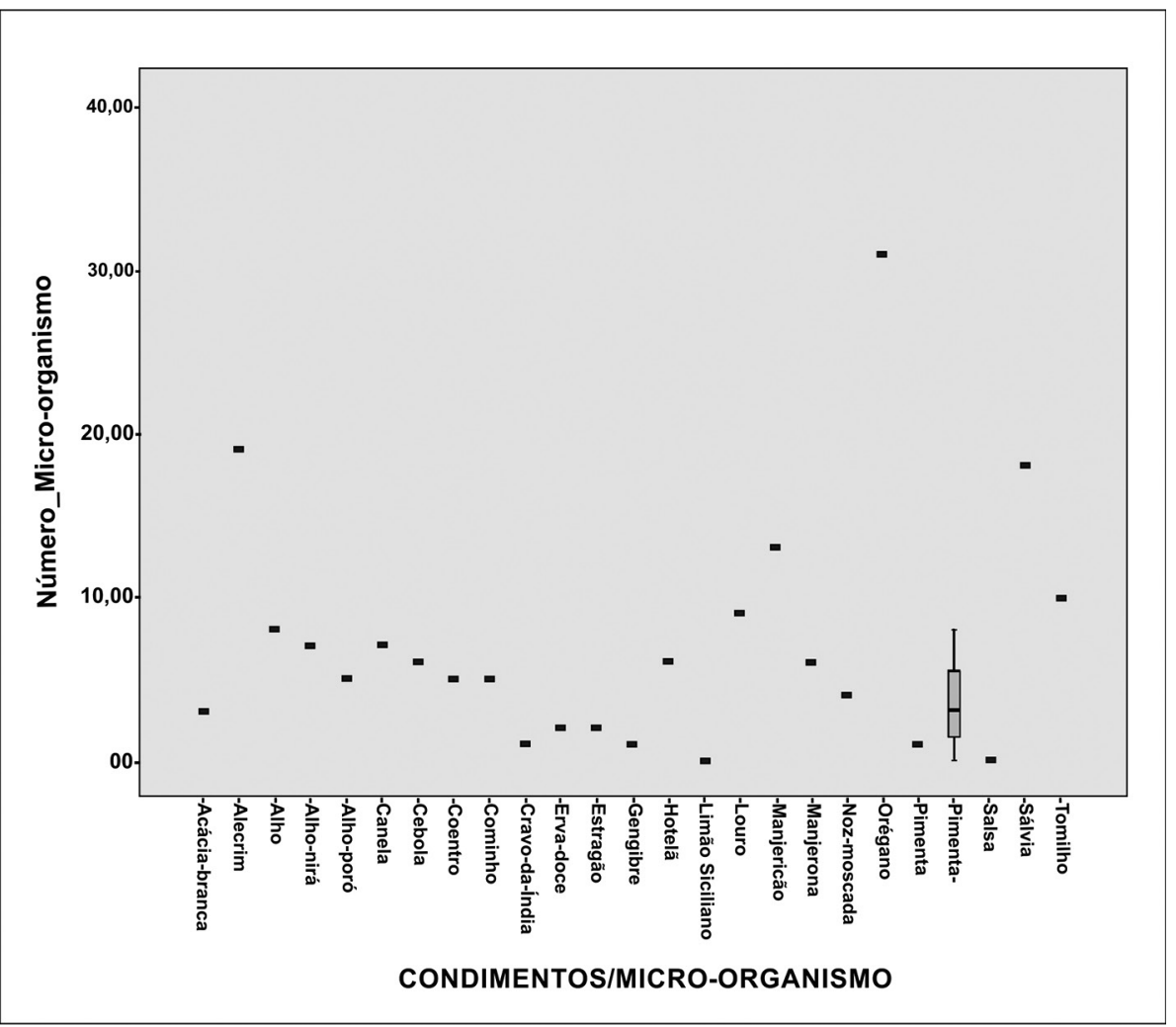

Figura 2 - Dispersão da frequência de relatos acerca da efetividade antimicrobiana em relação aos temperos, condimentos e especiarias. Software IBM SPSS Statistics Base 22.0, Niterói, 2016.

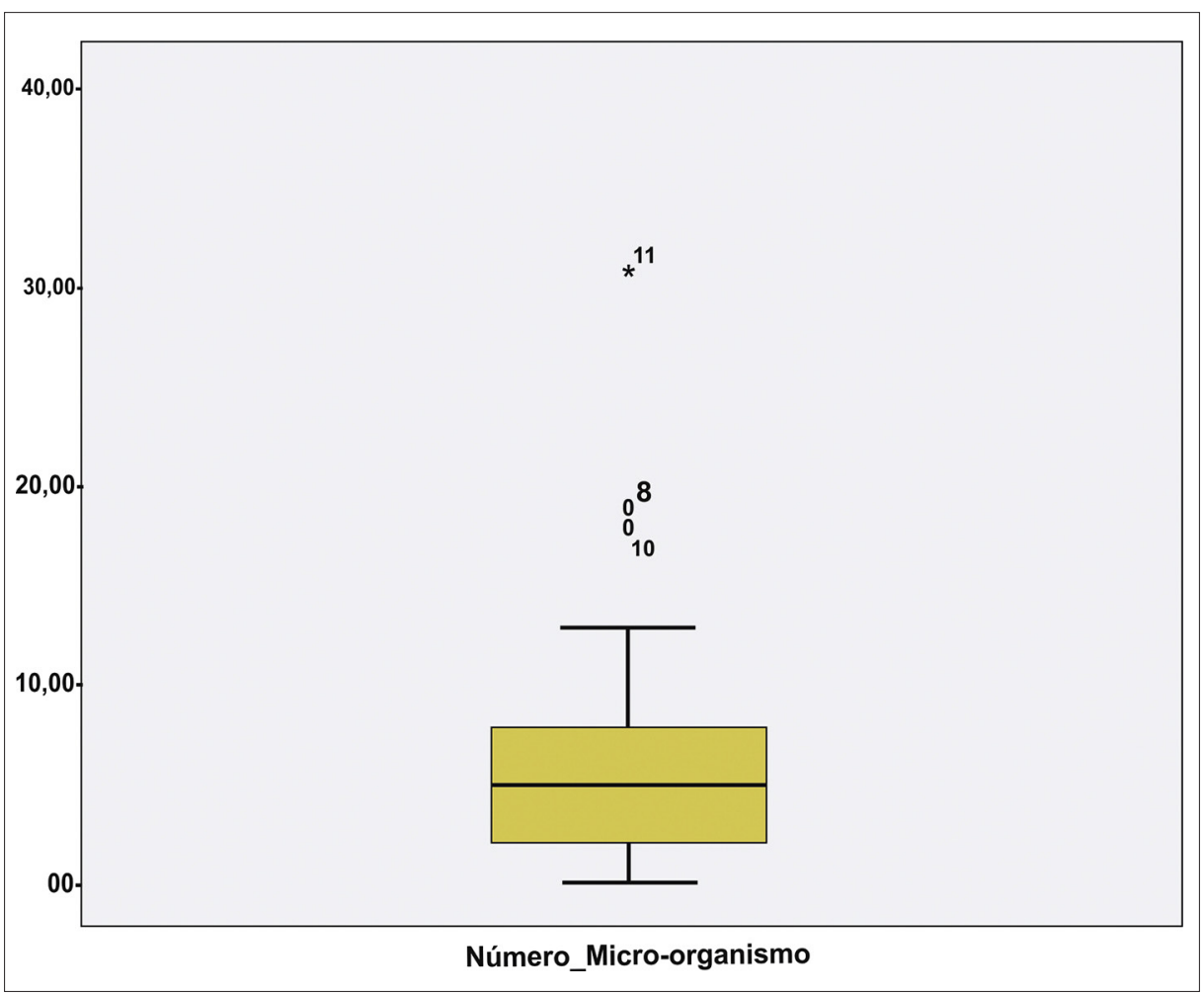

Figura 3 - Representação gráfica "Box Plot" das variáveis condimentos versus micro-organismo. Software IBM SPSS Statistics Base 22.0, Niterói, 2016. 
A posição da linha mediana no retângulo informa sobre a assimetria da distribuição. Nesta pesquisa, a distribuição dos dados mostrou-se simétrica, pois a mediana está no centro do retângulo.

O comprimento das linhas fora do retângulo (algumas vezes chamadas de "whisquers") informam sobre a cauda da distribuição. Os valores fora de Q1-1.5*(Q3-Q1) e Q3+1.5*(Q3 -Q1) geralmente são chamados de "outside" e devem ser investigados como possíveis "outliers" (pontos desgarrados). Neste sentido, o valor 11 refere-se ao Orégano; o valor 8, ao Alecrim e o valor 10 refere-se à Sálvia. Destarte, são os “outliers" dessa variável, indicando que seus valores são muito maiores que os encontrados nos demais temperos, sendo, pois, os condimentos de maior efetividade antimicrobiana. O asterisco representa o valor extremo obtido (orégano).

\section{DISCUSSÃO}

A maioria dos estudos (71,3\%) que compuseram esta revisão sistemática de literatura foi produzida nas Regiões Sudeste e Sul. Uma possível explicação para esses achados seriam as grandes disparidades de desenvolvimento existentes entre as grandes macrorregiões brasileiras. Os indicadores científicos e tecnológicos existentes revelam, sem dúvida, um grande desnível da base técnico-científica entre as grandes regiões que compõem o território brasileiro (Barros, 2000).

O presente estudo encontrou situação contraria ao descrito por Shelton (1928), quando afirmava que os temperos e condimentos não possuem quase nenhum nutriente de grande relevância para os seres humanos e que por isso, não há nenhuma justificativa para utilizá-los.

Tirante os benefícios propiciados à saúde, inúmeras pesquisas têm ratificado o efeito inibidor dos condimentos no desenvolvimento dos micro-organismos deteriorantes, bem como dos patogênicos, transmitidos aos seres humanos pela ingestão de alimentos de origem animal, todavia, poucos são os trabalhos referentes uso de especiarias com a finalidade inibitória de agente patogênicos em pescado.

Neste sentido, esta pesquisa aponta o orégano como condimento mais eficaz na ação antimicrobiana dentre os condimentos estudados até a atualidade, pois tem amplo registro na literatura, inclusive validando o descrito por Marino et al. (2001), que verificaram que o orégano possui uma riqueza em compostos fenólicos, que além de potentes antioxidantes são creditados como sendo os responsáveis por sua atividade antimicrobiana, pois são capazes de dissolverem-se na membrana microbiana, penetrando na célula. Desta forma, podem alterar os mecanismos essenciais para o metabolismo microbiano, causando a morte das bactérias.

Em dez estudos selecionados para a revisão, o óleo essencial de orégano foi efetivo sobre diversas bactérias; em dois estudos, foi eficiente na prevenção da oxidação; e também em dois estudos, teve um efeito pronunciado na inibição do desenvolvimento de fungos. O presente estudo reafirmou os resultados de Silva et al. (2010), os quais ratificam que os óleos essenciais de orégano, por possuírem p-cimeno, gama-terpineno e carvacrol, têm o seu efeito antimicrobiano potencializado.

Ademais, de acordo com Rossato (2010), a elaboração de hambúrguer com carne mecanicamente separada (CMS) de tilápia é uma alternativa ao consumo de alimentos à base de pescado, bem como o uso do orégano como antioxidante, além de prevenir a oxidação, favorece a sua aceitação pelos provadores. 
Araújo et al., 2015, determinaram a composição química e avaliaram a atividade antibacteriana do óleo essencial de orégano frente às cepas de Escherichia coli, Staphylococcus aureus e Salmonella choleraesuis. Todos os patógenos testados apresentaram sensibilidade ao óleo essencial de orégano, sendo observado maior ação do óleo sobre bactérias Gram-positivas.

Em sete pesquisas apuradas nesta revisão, o alecrim foi eficiente em face de muitos micro-organismos. Situação similar é descrita desde Chipault et al. (1952), que avaliaram a ação de 32 especiarias, das quais o alecrim foi considerado o mais eficaz. Essa conclusão também está de acordo com o estudo de Piedade (2007), quando cita que as técnicas cromatográficas analíticas têm permitido identificar os compostos antioxidantes, não somente nas especiarias tradicionais, como também em ervas aromáticas, entre elas, o alecrim. Esses compostos antioxidantes são de natureza fenólica, o que explica tal atividade. Desses compostos, talvez o de maior interesse seja o ácido rosmarínico, muito mais potente do que o hidroxi-butinasol (BHA) e o hidro-butiltolueno (BHT).

Nas condições experimentais utilizadas por Ribeiro (2011), com base nos resultados obtidos em sua dissertação, pôde-se concluir que o óleo essencial das folhas frescas de Rosmarinus officinalis L. (alecrim) possui ação inibitória frente à cepa de Escherichia coli EC16, in vitro e na matriz alimentícia, podendo o mesmo ser usado no controle desse micro-organismo.

Dos resultados dos artigos analisados, cinco fizeram referência às potencialidades antimicrobianas da sálvia. No estudo realizado por Larosa et al. (2012), os resultados mostraram a possibilidade de se elaborar recheios com CMS de tilápia + corte em " $\mathrm{v}$ " como uma alternativa para o consumo de alimentos à base de pescado e a sálvia é o antioxidante natural mais eficiente para retardar as reações de oxidação. Contudo, entre os recheios elaborados com antioxidantes naturais, o orégano foi o que mais agradou ao paladar, provavelmente, por ser entre as especiarias a mais utilizada na culinária, e assim, os provadores estarem habituados com o seu sabor.

Na presente revisão, foram identificados seis estudos que analisaram a antimicrobiana do manjericão. Mejlholm \& Dalgaard (2002) avaliaram o efeito antimicrobiano dos óleos essenciais de orégano, louro, manjerona, sálvia e manjericão em face da Photobacterium phosphoreum e determinaram o efeito desses óleos na vida de prateleira de filetes (MAP) de bacalhau embalados sob atmosfera modificada e observaram haver redução no crescimento bacteriano, bem como obtiveram vida de prateleira estendida $11-12$ dias para $21-26$ dias a $2^{\circ} \mathrm{C}$.

Muito embora Santos (2011) concluir não haver atividade antibacteriana do limão siciliano em Staphylococcus aureus, Escherichia coli e Salmonella cholerasuis, o estudo de Silva (2014) encontrou situação contrária, quando afirma que o limão siciliano foi o condimento que apresentou a maior atividade antimicrobiana em face de bactérias Gram-positivas (Listeria monocytogenes, Clostridium perfringens, Bacillus cereus, Staphylococcus aureus, Enterococcus faecium, Enterococcus faecalis, e Staphylococcus epidermidis) e Gram-negativas (Salmonella enterica, Escherichia coli, e Pseudomonas aeruginosa).

Brilhante et al. (2015) investigaram o potencial antimicrobiano in vitro de extratos de caule, folhas, flores, vagens e sementes de Moringa oleifera contra Vibrio spp. presentes na água do camarão Macrobrachium amazonicum. O melhor resultado foi obtido com o extrato etanólico de vagens, que inibiu três estirpes do Vibrio cholerae, Vibrio vulnificus, Vibrio mimicus. O extrato de clorofórmio de flores foi eficaz contra todas as estirpes de Vibrio cholerae. No entanto, os extratos de etanol de sementes e caules mostrou baixa eficácia em inibir o crescimento bacteriano. 
As limitações deste estudo de revisão sistemática de literatura referem-se a não contemplação de trabalhos alusivos à presença de corpo estranhos e de micro-organismos patogênicos e/ou deteriorantes nas próprias especiarias, e o seu reconhecimento como possíveis veículos de inserção de micro-organismos em alimentos. $\mathrm{O}$ uso de condimentos e especiarias tanto em nível industrial quanto doméstico, apresenta muitos benefícios, mas também alguns riscos, sobretudo em função da adição de outros materiais e/ou substâncias que não fazem parte da composição do condimento (simples ou preparado).

Além disso, embora em todos os estudos selecionados tenham sido guiados pelo protocolo PRISMA, a pesquisa não contemplou textos acerca das concentrações necessárias de óleos essências para que estas possam ser consideradas fontes de agentes antimicrobianos capazes de serem utilizados como compostos alternativos objetivando a segurança microbiológica de alimentos.

Apesar das limitações, esta revisão poderá servir de base para outros estudos, mormente, para se verificar a ação dos temperos, condimentos e especiarias como uma proposta viável no combate do crescimento de bactérias, leveduras, fungos filamentosos e síntese de toxinas microbianas, bem como na inibição ou retardamento da oxidação do pescado.

\section{CONCLUSÃO}

Infere-se que a utilização dos temperos, condimentos e especiarias é uma boa opção no combate ao crescimento de bactérias, leveduras, fungos filamentosos e síntese de toxinas microbianas, bem como na inibição ou retardamento da oxidação do pescado, pois este trabalho evidenciou a potencialidade desses vegetais como fontes de agentes antimicrobianos capazes de serem utilizados como compostos alternativos para o alcance da segurança microbiológica de alimentos.

Ademais, os achados de consideráveis propriedades antimicrobianas nas ervas estudas vêm ao encontro dos anseios de parte dos consumidores e da própria legislação, haja vista requererem a produção de alimentos com baixos níveis de aditivos químicos.

Os resultados demonstram que, apesar das ações aromatizantes em alimentos, as especiarias e condimentos também podem contribuir com um efeito antimicrobiano contra agentes patogênicos, constituindo-se num benefício à saúde quando incorporadas na alimentação. Assim, os produtos de ação comprovada apresentados nesta revisão, principalmente orégano, alecrim, sálvia, manjericão e tomilho, podem ser considerados agentes antimicrobianos naturais, podendo ser usados como alternativas eficientes aos conservantes químicos.

No futuro, seriam necessários mais estudos, no sentido de determinar as espécies de plantas ideias para a extração de óleos essenciais com atividade antimicrobiana de modo a que, posteriormente, possam ser determinadas as concentrações mínimas inibitórias para agir sobre bactérias patogênicas de alimentos. Mister se faz ainda proceder a testes de aceitabilidade e alergenicidade por parte do consumidor humano para que se possa contemplar todos esses produtos de origem vegetal como alimentos operativos e seguros.

\section{REFERÊNCIAS BIBLIOGRÁFICAS}

Amagliani, G.; Brandi, G. \& Schiavano, G.F. Incidence and role of Salmonella in sea food safety. Food Research International. v.45, p.780-788, 2012. Disponível em: https:/ / www.rese- 
archgate.net/publication/251629215_Incidence_and_role_of_Salmonella_in_seafood_safety_Food_Res_Int. Acesso em: 22 de janeiro de 2016.

Araújo, C.D.; Carvalho, H.H.C.; Souto, S.A.; Sobreiro, A.A. \& Wiest, J.M. Atividade antibacteriana in vitro de extratos de alho nirá (Allium tuberosum Rottler ex Spreng.). Rev. Bras. Plantas Med. Botucatu. v. 11, n.3, p.263-268, 2009. Disponível em: http://www.lume.ufrgs. br/bitstream/handle/10183/108125/000757097.pdf?sequence=1. Acesso em: 20 de janeiro de 2016.

Araújo, L.S.; Araújo, R.S.; Serra, J.L. \& Nascimento, A.R. Composição química e susceptibilidade do óleo essencial de orégano (Origanum vulgare L., família Lamiaceae) frente à cepas de Escherichia coli, Staphylococcus aureus e Salmonella choleraesuis. Bol. Cen. Pesq. Proces. Alimentos (BCEPPA). Curitiba, v.33, n.1, p.73-78, 2015. Disponível em: http:/ / revistas.ufpr. br/alimentos/article/view/43808. Aceso em: 23 de maio de 2016.

Bara, M.T.F.\& Vanetti, M.C.D. Estudo da atividade antibacteriana de plantas medicinais, aromáticas e corantes naturais. Rev. Bras. Farmacognosia, v. 7-8, n. 1, São Paulo, p.22-34, 1998.Disponível em: http://www.scielo.br/scielo.php?script=sci_arttext\&pid=S0102-695X1998000100003\&lng=en\&nrm=iso. Acesso em: 19 de janeiro de 2016.

Barros, F.A.F. Os desequilíbrios regionais da produção técnico-científica. São Paulo em Perspectiva, São Paulo, v. 14, n. 3, p.12-19, 2000. Disponível em: http://www.scielo.br/ scielo.php?script=sci_arttext\&pid=S0102-88392000000300004\#back1. Acessado em: 19 de janeiro de 2016.

Brasil. Ministério da Agricultura, Pecuária e Abastecimento. Departamento Nacional de Inspeção de Produtos de Origem Animal. Regulamento da Inspeção Industrial e Sanitária de Produtos de Origem Animal - RIISPOA. Brasília: MAPA, 1952. 154 p. Aprovado pelo Decreto $n^{\circ}$ 30.691, de 29 de março de 1952. Disponível em: http://www.agrodefesa. go.gov.br/index.php/publicacoes/insp-legislacoes/federal/99-decreto-30691/file. Acesso em: 29 de fevereiro de 2016.

Brilhante, R.S.N.; Sales, J.A.; Sampaio, C.M.S.; Barbosa, F.G.; Araújo Neto Paiva, M.; Guedes, G.M.M.; Alencar, L.P.; Ponte, Y.B.; Bandeira, T.J.P.G.; Moreira, J.L.B.; CasteloBranco, D.S.C.M; Pereira-Neto, W.A.; Cordeiro, R.A.; Sidrim, J.J.C. \& Rocha, M.F.G. Vibrio spp. from Macrobrachium amazonicum prawn farming are inhibited by Moringa oleifera extracts. Asian Pacific J. Trop. Med., v.8, n.11, p. 919-922, 2015. Disponível em: http:/ / www. sciencedirect.com/science/article/pii/S1995764515001698. Acesso em: 13 de abril de 2016.

Burt, S.A. Essential oils: their antibacterial properties and potential applications in foods. Inter. J. Food Microbioloby, v. 94, p. 223-253, 2004. Disponível em: http:/ / www.ncbi.nlm.nih. gov/pubmed/15246235.

Carneiro, H. Especiarias. In: Beting, G. História de A a Z, v.3: Idade Moderna. Rio de Janeiro, Duetto, p. 74-75, 2009.

Carvalho, H.H.C., Cruz, F.T. \& Wiest, J.M. Atividade antibacteriana em plantas com indicativo etnográfico condimentar em Porto Alegre, RS/Brasil. Rev. Bras. Plantas Medicinais, Botucatu, v.7, n.3, p.25-32, 2005. Disponível em: http:/ / www.sbpmed.org.br/download/ issn_05_3/artigo4_v7_n3.pdf. Acesso em: 21 de janeiro de 2016.

Chipault, J.R.; Mizuno, G.R.; Hawkins, J.M. \& Lundberg, W.O. The antioxidant properties of natural spices. Food Research, Chicago, v.17, n.1, p.46-55, 1952. Disponível em: http:// 
onlinelibrary.wiley.com/doi/10.1111/j.1365-2621.1952.tb16737.x/abstract. Acesso em: 30 de maio de 2016.

Costa, A.C.; Santos, B.H.C.; Santos Filho, L. \& Lima, E.O. Atividade antibacteriana do óleo essencial de Origanum vulgare L. (Lamiaceae) contra bactérias multiressistentes isoladas de pacientes nosocomial. Braz. J. Pharmacognosy, v.19, n.1, p. 236-241, 2009. Disponível em: http://www.scielo.br/pdf/rbfar/v19n1b/a10v191b.pdf. Acesso em: 24 de maio de 2016.

Costa, R.A. Bioatividade in vitro de extratos etanólicos de sementes de moringa oleifera frente a estirpes de vibrio portadoras de fatores de virulência e resistentes a antimicrobianos, isoladas da hemolinfa do camarão litopenaeus vannamei. 2011. 103f. Tese (Doutorado em Engenharia de Pesca) Programa de Pós-Graduação em Engenharia de Pesca. Centro de Ciências Agrárias. Universidade Federal do Ceará, Fortaleza, Ceará. 2011. Disponível em: 21 de janeiro de 2016.http://repositorio.ufc.br/bitstream/riufc/14121/1/2011_tese_racosta.pdf. Acesso em: 17 de dezembro 2015.

Deans, S. G. \& Ritchie, G. Antibacterial properties of plant essencial oils. International J. Food Microbiology, v.5, n.2, p.165-180, 1987. Disponível em: http://www.sciencedirect. com/science/article/pii/0168160587900341. Acesso em 20 de dezembro de 2015.

Del Ré, P.V. \& Jorge, N. Especiarias como antioxidantes naturais: aplicações em alimentos e implicação na saúde. Rev. Bras. Plantas Medicinais, Botucatu, v.14, n.2, p.389-399, 2012. Disponível em: http://www.scielo.br/scielo.php?script=sci_arttext\&pid=S1516 -05722012000200021. Acesso em 23 de abril de 2016.

Gandra, E.A.; Nogueira, M.B.; Chim, J.F.; Machado, M.R.G.; Rodrigues, R.S.; Zambiazi, R.C.; Voloski, F.L.; Schneid, I. \& Freitas, P.F. Potencial antimicrobiano e antioxidante de extratos vegetais de alecrim, erva doce, estragão e orégano. Rev. Ciên. Tec., n.20, 2013. Disponível em: http://www.scielo.org.ar/scielo.php?script=sci_arttext\&pid=S185175872013000200004. Acesso em: 13 de janeiro de 2016.

Gaspar, J.; Vieira, R. \& Tapia, M. Aspectos sanitários do pescado de origem de água doce e marinha, comercializado na feira de Gentilândia, Fortaleza, Ceará. Rev. Ciên. Tec., p.2023.1997. Disponível em: http://www.scielo.br/scielo.php?script=sci_nlinks\&ref=000066 \&pid=S0036-4665200100030000500007\&lng=pt. Acesso em: 12 de abril de 2016.

Inatani, R.N.; Nakatani, Fuwa H.; Seto, H. Structure of a new antioxidative phenolic diterpene isolated from rosemary (Rosmarinusofficinalis L.). Agr. Biol. Chem. Tokio, v. 46, n. 6, p.1661-1666, 1982. Disponível em: http:/ / www.tandfonline.com/doi/pdf/10.1080/00021 369.1982.10865273. Acesso em: 15 de janeiro de 2016.

Kruger, M.F. Controle de Listeria monocytogenes em linguiça frescal refrigerada através do uso de óleo essencial de orégano e nisina. 2006. 74f. Dissertação (Pós-graduação em Ciência dos Alimentos) - Faculdade de Ciências Farmacêuticas, Universidade de São Paulo, São Paulo, 2006. Disponível em: http://www.teses.usp.br/teses/disponiveis/9/9131/tde-13092006110306/pt-br.php. Acesso em: 30 de março de 2016.

Larosa, G.; Carvalho, M.R.B.; Vidotti, R.M.; Lima, T.M.A. \& Alves, V.F. Elaboração de produto cárneo de tilápia com antioxidantes visando sua utilização como recheio ou acompanhamento da refeição. Alimentos e Nutrição, Araraquara, v.23, n.4, p. 609-617, 2012. Disponível em: http:/ / serv-bib.fcfar.unesp.br/seer/index.php/alimentos/article/viewArticle/609. Acesso em: 23 de maio de 2015. 
Liston, M.S. Estudo da composição e aplicação do óleo essencial de Origanum vulgare L. Como agente antimicrobiano em sururu (Mytella falcata). 2013. 73f. Dissertação (Centro de Ciências Exatas e Tecnologia) - Programa de Pós-graduação em Química, Universidade Federal do Maranhão, São Luís, Maranhão. 2013. Disponível em: http://www.tedebc.ufma.br/ / tde_ busca/arquivo.php?codArquivo=908. Acesso em: 30 de dezembro de 2015.

Malta, M.; Cardoso, L.O.; Bastos, F.I.; Magnanini, M.M.F. \& Silva, C.M.F.P. Iniciativa STROBE: subsídios para a comunicação de estudos observacionais. Rev. Saúde Pública 2010; v.44, n.3, p.559-565, 2010. Disponível em: http://www.scielo.br/scielo.php?script=sci_art text\&pid=S0034-89102010000300021. Acesso em: 20 de dezembro de 2015.

Marino, M.; Bersani, C. \& Comi, G. Impedance measurements to study the antimicrobial activity of essential oils from Laminaceae and Compositae. Int. J. Food Microbiol., v.67, n.3, p. 187-195, 2001. Disponível em: http://www.sciencedirect.com/science/article/pii/ S0168160501004470. Acesso em: 28 de dezembro de 2015.

Mejlholm, O. \& Dalgaard, P. Antimicrobial effect of essential oils on the seafood spoilage micro-organism Photobacterium phosphoreum in liquid media and fish products. Letters Applied Microbiology. Dinamarca, v.34, n.1, p.27-31. 2002. Disponível em: http://www. ncbi.nlm.nih.gov/pubmed/ ?term=Antimicrobial+effect+of+essential+oils+on+the+seafo od+spoilage+micro-organism+Photobacterium +phosphoreum+in+liquid+media+and+fi sh+products. Acesso em: 20 de janeiro de 2016.

Melo, E.A.; Mancini, J.F.; Guerra, N.B. \& Maciel, G.R. Atividade antioxidante de extratos de coentro (Coriandrum sativum L.). Ciênc. Tecnol. Aliment., v. 23, supl. Campinas , p.195-199, 2003. Disponível em: http://www.scielo.br/scielo.php?script=sci_arttext\& pid=S0101-20612003 000400036\&lng=en\&nrm=iso\&tlng=pt. Acesso em: 12 de fevereiro de 2016.

Moher, D.; Liberati, A.; Tetzlaff, J. \& Altman, D. G. A. Preferred Reporting Items for Systematic Reviews and Meta-Analyses: The PRISMA statement. Annals of Internal Medicine, Philadelphia v. 151, n.4, p.264-269, 2009. Disponível em: http://annals.org/article. aspx?articleid=744664. Acesso em: 23 de dezembro de 2015.

Ozcan, M. \& Erkman, O. Antimicrobial activity of the essencial oils of Turkinsh plant spices. European Food Research and Technology, v. 212, n. 6, p. 658-660, 2001. Disponível em: http:/ / link.springer.com/article/10.1007\%2Fs002170100310\#page-1. Acesso em: 20 de janeiro de 2016.

Pereira, A.A.; Piccoli, R.H.; Batista, N.N.; Camargos, N.G. \& Oliveira, M.M.M. Inativação termoquímica de Escherichia coli, Staphylococcus aureus e Salmonella enterica Enteritidis por óleos essenciais. Ciência Rural, Santa Maria, v.44, n.11, p. 2022-2028, 2014. Disponível em: http:/ / www.scielo.br/scielo.php?script=sci_arttext\&pid=S0103-84782014001102022. Acesso em: 24 de abril de 2016.

Piedade, K. R. Uso de ervas aromáticas na estabilidade oxidativa de filés de sardinha (Sardinella brasiliensis) processados. 2007. 161f. Dissertação (Ciência e Tecnologia de Alimentos) Escola Superior de Agricultura "Luiz de Queirós", Universidade de São Paulo, Piracicaba, São Paulo, 2007. Disponível em http://www.teses.usp.br/teses/disponiveis/11/11141/ tde-08112007-114206/pt-br.php. Acesso em: 30 de janeiro de 2016.

Radaelli, M.; Silva, B.P.; Weidlicha, L.; Hoehne, L.; Flach, A.; Costa, L.A.M.A. \& Ethur, E.M. Antimicrobial activities of six essential oils commonly used as condiments in Brazil against 
Clostridium perfringens. Braz. J. Microbiology, São Paulo, v. 47, n. 2, p. 424-430, 2016. Disponível em: http://www.scielo.br/pdf/bjm/v47n2/1517-8382-bjm-47-02-0424.pdf. Acesso em: 12 de fevereiro de 2016.

Resende, B.M. \& Stelato, M.M. Atividade de óleos essenciais de plantas utilizadas na Culinária sobre bactérias patogênicas ou Deteriorantes de alimentos. In: Encontro de iniciação científica da puc, 14. 2009, Campinas. Anais... Campinas: Fapic, 2009. Disponível em: https:/ / www.puc-campinas.edu.br/websist/portal/pesquisa/ic/pic2009/resumos/2009824_201052_207352239_res3F8.pdf. Acesso em: 20 de janeiro de 2016.

Ribeiro, D.S. Avaliação da atividade antimicrobiana do óleo essencial de alecrim (Rosmarinus officinalis L.) frente a bactérias isoladas de alimentos: estudos in vitro e em matriz alimentícia. 2011. 102f. Dissertação (Mestrado em Ciência de Alimentos) - Programa de Pós-Graduação em Ciência de Alimentos, Faculdade de Farmácia, Universidade Federal da Bahia, Salvador, Bahia de Todos os Santos. 2011. Disponível em: https:/ / repositorio.ufba.br/ri/bitstream/ ri/8725/1/Daniele\%20Silva\%20Ribeiro.pdf. Acesso em 23 de junho de 2016.

Rossato, A.S. Uso de antioxidantes naturais em hambúrgueres preparados com carne mecanicamente separada de tilápia. 2010. 88p. Tese (Doutorado em Alimentos e Nutrição) Departamento de Alimentos e Nutrição, Faculdade de Ciências Farmacêuticas, Universidade Estadual Paulista (UNESP), Araraquara, São Paulo, 2010. Disponível em: http://repositorio.unesp.br/handle/11449/100878. Acesso em 23 de março de 2016.

Santos, J.C.; Carvalho Filho, C.D.; Barros, T.F. \& Guimarães, A.G. Atividade antimicrobiana in vitro dos óleos essenciais de orégano, alho, cravo e limão sobre bactérias patogênicas isoladas de vôngole. Semina: Ciências Agrárias, Londrina, v.32, n.4, p.1557-1564. 2011. Disponível em: http://www.redalyc.org/articulo.oa?id=445744110029. Em 21 de maio de 2016.

Shelton, H.M. Human life: its laws and philosophy. Oklahama: How to live Pub. Co. 1928. Disponível em: https:/ / books.google.com.br/books?id=dcssshFW7REC\&printsec=frontc over\&hl=pt-BR\&source=gbs_ge_summary_r\&cad=0\#v=onepage\&q\&f=false. Acesso em: 20 de janeiro de 2016.

Shea B.J.; Hamel C.; Wells G.A.; Bouter L.M.; Kristjansson E.; Grimshaw J.; Henry D.A. \& Boers M. AMSTAR is a reliable and valid measurement tool to assess the methodological quality of systematic reviews. J. Clin. Epidemiol., p.1013-1020, 2009. Disponível em: http:/ / amstar.ca/docs/Publication\%20-\%20AMSTAR\%20is\%20reliable.pdf. Acesso em: 13 de janeiro de 2016.

Silva, J.P.L.; Duarte-Almeida, J.M.I.; Perez, D.V. \& Franco, B.D. G.M. Óleo essencial de orégano: interferência da composição química na atividade frente a Salmonella Enteritidis. Ciênc. Tecnol. Aliment. Campinas, v.30, n. 1, p.136-141. 2010. Disponível em: http:/ /www. scielo.br/scielo.php?script=sci_arttext\&pid=S0101-20612010000500021. Acesso em 20 de abril de 2016.

Silva, R.M.M. Avaliação da atividade antimicrobiana de condimentos portugueses e óleos essenciais de plantas aromáticas frente a bactérias patogénicas e/ou deteriorantes de alimentos. $100 \mathrm{f}$. Vila Real, Portugal, 2014. Dissertação (Mestrado em Segurança Alimentar) - Departamento de Ciências Veterinárias, Universidade de Trás-os-Montes e Alto Douro, Vila Real, Portugal, 2014. Disponível em: http://repositorio.utad.pt/bitstream/10348/6188/1/msc_rmmsilva.pdf. Acesso em: 23 de março de 2016. 
Trajano, V.N.; Lima, E.O.; Souza, E.L. \& Travassos, A.E.R. Propriedade antibacteriana de óleos essenciais de especiarias sobre bactérias contaminantes de alimentos. Ciênc. Tecnol. Aliment. v.29, n.3, pp.542-545. 2009. Disponível em: http://www.scielo.br/ scielo.php?pid=S0101-20612009000300014\&script=sci_abstract\&tlng=pt. Acesso em 20 de maio de 2016.

Wiest, J.M.; Carvalho, H.H.C.; Avancini, C.A.M. \& Gonçalves, A.R. Inibição e inativação in vitro de Salmonella spp. com extratos de plantas com indicativo etnográfico medicinal ou condimentar. Arq. Bras. Med. Vet. Zootec., v.61, n.1, p.119-127. 2009. Disponível em: http:// www.scielo.br/pdf/abmvz/v61n1/v61n1a17.pdf. Acesso em: 23 de janeiro de 2016. 